\title{
Alerts for policy makers extracted from papers published during 2015 in volume 7 of Food Security
}

\author{
Richard Strange ${ }^{1}$
}

Published online: 14 January 2016

(C) Springer Science+Business Media Dordrecht and International Society for Plant Pathology 2016

This item summarizes very briefly some of the papers published in volume 7 of Food Security for the year 2015, drawing attention to current and future critical issues in food and nutrition insecurity and measures that could be adopted to ameliorate them. Papers are arranged according to the three environments designated in the strap line of the journal - the Physical Environment, the Biological Environment (divided into four sections) and the Socio-Political and Economic Environment (divided into six sections). It is hoped that Policy Makers concerned with food and nutrition security will note the papers relevant to their particular sphere of influence and that they will be inspired to take early action. Numbers after each entry refer to the pages on which the papers may be found in Volume 7 of the journal.

\section{The physical environment}

1. Decrease in potential crop yield in China owing to urban expansion: Luo $\mathrm{Li}$ and associates found that potential crop yields decreased by 13 million tons and 22 million tons during the decades 1990-2000 and 20002010, respectively, as calculated by the Global Agro-Ecological Zones (GAEZ) model, owing to urban expansion. Areas of lost potential yield were identified, providing useful information for future policies concerning land use (pp 33-43).

2. Heavy metal pollution and health risks in Hunan Province, China: Ming Lei and associates used hazard

Richard Strange

r.strange@ucl.ac.uk

1 University College London, Gower Street, London WC1E 6BT, UK indexes to measure the human health risk of consuming white rice grown in mining areas in Hunan Province, China. The major contributor to the risk, apart from one area, was cadmium (pp 45-54).

3. Water productivity and food security: Dennis Wichelns argues that water productivity, the ratio between the output value and the water applied to a crop, is not a sufficient indicator of economic efficiency. It therefore cannot be relied upon to determine adjustments to regional or farm level allocations of water (pp 247-260).

4. Soil degradation: Jane Rickson and associates call attention to the loss of an estimated 12 million hectares of agricultural land every year due to degradation. Comprehensive soil conservation practices are required to stem this loss (pp 351-364).

5. Water scarcity in China: Feng Huan and associates draw attention to China's growing water scarcity and use data from 1990 to 2010 to show that there is a slow declining trend in precipitation and internally renewable water resources, and that 12 out of the 13 breadbasket provinces already face water shortages (pp 933-944).

6. Food trade as a mechanism for circumventing national water scarcity: Michael Gilmont suggests there is significant potential for Middle East and North African (MENA) countries to overcome their agricultural water needs by importing staple crops from more water abundant countries (pp 1113-1131).

7. Tropical agriculturalisation: Mark Mulligan examines non-agricultural lands, which are most suitable for pasture and crop land, and identifies countries that are most likely to be able to contribute to food production in the future. He also projects forward the effects of potential climate change on water flow between the tropics and the rest of the world and predicts that there will be greater water availability in South America (pp 1133-1152). 
8. The socio-cultural, institutional and gender aspects of the water transfer-agribusiness model for food and water security. Lessons learned from Peru: Juana Vera Delgado reviews 'Large Scale Irrigation' projects, which have the objectives of making the desert bloom and increase agro-exports from Peru. Although they did so, it was at the cost of local environmental degradation, social unrest and gender disparities, factors that should be taken into account when planning large-scale irrigation projects in the future (pp 1187-1197).

\section{The biological environment: productivity and constraints}

\section{Food production}

1. Conservation agriculture in Zimbabwe: Christian Thierfelder and associates found that long-term conservation agriculture in an area of low soil fertility and erratic rainfall out yielded conventional agriculture. For maize the increase was up to $235 \%(1761 \mathrm{~kg} / \mathrm{ha})$ and for legumes $173 \%$ (26 kg/ha) (pp 15-31).

2. Genomic Breeding: John Rivers and associates call attention to the benefits of genomic breeding, resulting from new generation sequencing and 'big data'. These include accelerated crop improvement in such aspects as yield, quality and resilience (pp 375-382).

3. Benefits of levelling land by laser in the Indo-Gangetic plains: Jeetendra Aryal and associates show that laser levelling of land reduced the amount of time required for irrigation in a rice-wheat system and hence the electricity used for pumping as well as increasing yield (pp 725738).

4. Environmental impacts and constraints associated with the production of major food crops in Sub-Saharan Africa and South Asia: Travis Reynolds and associates point out that although the production of major food crops is often limited by environmental factors, frequently the growth of crops themselves have detrimental effects. These include soil degradation and erosion, loss of wild biodiversity, loss of food crop genetic diversity, soil water depletion, soil and water contamination and the emergence of new pests and diseases (pp 795-822).

5. Improved propagation methods to raise the productivity of yam: Beatrice Aighewi and associates point out that yam (Dioscorea rotundata) is an important staple in West Africa, yet efficient propagation is a major hurdle to be overcome. Further research is required to enable the production of disease free propagation material en masse (pp 823-834).
6. Limits of increasing food production with irrigation: Mikhail Smilovic and associates propose a method for estimating current and potential contribution of irrigation sources to agricultural production and food security in India. The method can easily be applied to other countries and could therefore be of considerable value to policy makers (pp 835-856).

7. Labour not land constrains food self-sufficiency in Mozambique: Wilson Leonardo and associates found that lack and poor quality of labour, particularly at weeding time, rather than lack of land, was the more important constraint for self-sufficiency smallholders in Mozambique (pp 857-874).

8. Appropriate mechanization in Eastern and Southern Africa (ESA): Frédéric Baudron and associates found that two-wheeled tractors (rather than the four-wheeled type, tried decades ago, and which never caught on) to be a highly appropriate form of mechanization in ESA, which has the potential to reduce much of the drudgery associated with farm work (pp 889-904).

9. Rice yields in the middle and lower reaches of the Yangtze River: Lechan Yang and associates examined the effect of climate variables on yields of the three cropping systems used in this region but found that increase in the minimum purchase price of rice improved yields as farmers were motivated to increase investment in inputs (pp 951-963).

10. Benefits of zero tillage in the Indo-Gangetic plains: Alwin Keil and associates found that zero-tillage (ZT) practices increased yields of wheat across different agro-ecological zones by $498 \mathrm{~kg} \mathrm{ha}^{-1}$. This, together with cost savings in cultivation, amounted to an annual increase in total income for households of $6 \%$ (pp 983-1001).

11. Reconciling food and water security objectives of MENA and Sub-Saharan Africa: Timothy Williams asks if there is a role for large-scale agricultural investments and points out that many projects have so far performed poorly or have been abandoned. He argues that large-scale agricultural investments should incorporate ecosystems management practices and smallholder inclusive business models. Such projects could reconcile the food and water security objectives of both the Middle East and North African (MENA) region and Sub-Saharan Africa (SSA) as well as promote sustainable intensification of agriculture and improvement of rural livelihoods in SSA (pp 1199-1209).

12. Horticultural practice and germplasm conservation: a case study in a rural population of the Patagonian steppe: Cecilia Eyssartier and associates document the horticultural practices and germplasm conservation of a rural population of the northwestern Patagonian steppe, who had been forcibly relocated in 1987 in order to accommodate the construction of the Piedra del Águila 
hydroelectric dam. A total of 166 species was cultivated or gathered. Food species were cultivated in vegetable-gardens mostly from saved seed. Gathered species were mainly used for medicinal purposes (pp 1259-1271).

13. Sustainability spaces for complex Agri-Food Systems: Stephen Whitfield and associates point out that, because of the complexity of Agri-food systems, generic or narrow goals may give rise to conflicting policies. They therefore propose the concept of sustainable space for defining and monitoring sustainability priorities that could become the basis for effective management of complex systems (pp 1291-1297).

Fish

1. Putting fish back on the menu: Christophe Béné and associates point out the benefits of a diet containing fish and make a compelling case for integrating fish into the debate and future policy about food and nutrition security (pp 261-274).

\section{Insects}

1. Regulating entomophagy: Afton Halloran and associates point out that although the consumption of insects is a common practice in many parts of the world, there is little legislation governing conservation and protection of insects as a source of food, rather the accent has been on food safety and protection of consumers. They suggest that entomophagy should be viewed holistically and that future legislation should take into account its multi-dimensional nature (pp 739-746).

2. Stinkbugs as a source of food and cash in sub-Saharan African countries: Cathy Dzerefos and Ed Witkowski draw attention to the importance of the edible stinkbug Encosternum delegorguei both as a source of food, once the malodorous alarm pheromone is removed, and cash. They note that, in South Africa for example, almost four tons are harvested annually. However, this resource is threatened by overexploitation and unsustainable harvesting methods (pp 919-925).

\section{Pests, diseases and their control}

1. The coffee rust crises in Colombia and Central America: Jacques Avelino and associates point out that all the intense coffee rust epidemics in the last 37 years have been concurrent with suboptimal management caused by low profitability of the crop or increased costs of inputs. They advocate the establishment of resistant cultivars, the creation of early warning systems, the development of management systems adapted to climate change and training of personnel (pp 303-321).

2. Integrated pest management in East Africa: Building on the success of push-pull technology, which relies on companion crops to control the parasitic weed, Striga, and stemborers, Alice Murage and associates sought the potential of adoption of companion crops which were also 'climate-smart' in that they were more drought tolerant. Results were promising with an overall average of $87.8 \%$ of the total of 898 respondents in Tanzania, Kenya and Ethiopia willing to adopt (pp 709-724).

3. Farmers' willingness to pay for a village poultry vaccine service in Ethiopia: Zelalem Terfa and associates point out that chickens are a major source of protein and income supply in Ethiopia but are susceptible to Newcastle disease and Infectious bursal disease. In 2011, around 42.3 million poultry died of disease. The authors found that farmers recognised the value of vaccines and were willing to pay 80-87 Ethiopian Birr per annum for them (about 4 US dollars: pp. 905-917).

\section{The socio-economic and political environment}

\section{Assessing food insecurity}

1. A novel tool for understanding food insecurity as a range of experiences: Sheryl Hendriks proposes that food security should be viewed as a continuum and claims that the concept increases focus on less extreme but nevertheless urgent manifestations of food insecurity, more accurate targeting of interventions and better follow up and improved accountability for donor spending (pp 609-619).

2. Gendered food security in rural Malawi: why is women's food security status lower? Menale Kassie and associates found that the food security of female-headed households (FHHs) would improve significantly if they had the same resources as male-headed households (MHHs) but would still be below that of MHHs. This is because the returns to resources are greater for MHHs than FHHs (pp 1299-1320).

\section{Food sources and access to food}

1. Importance of wild foods in Timor-Leste: William Erskine and associates found that wild foods, principally lesser yam (Dioscorea esculenta), elephants foot yam (Amorphophallus paeonifolius) and bitter bean (Phaseolus lunatus), were critical food sources for about 
half the year in Timor-Leste, when more than $30 \%$ of households experienced 'hunger months' (pp 55-65).

2. Tradeoffs for Pacific Island populations between commercial fishing and fishing for home consumption: Graham Pilling and associates found that Pacific Island populations face a dilemma - do they obtain considerable economic benefit from licensing commercial fishing of tuna in their waters or fish for home consumption, thus ensuring better nutrition for their populations (pp 67-81)?

3. Training in women's home gardens improves vegetable production and consumption in Bangladesh: Pepijn Schreinemachers and associates found that training increased leafy vegetable production by $86 \%$, protein by $171 \%$, iron by $284 \%$, vitamin A by $189 \%$ and vitamin $\mathrm{C}$ by $290 \%$. Involvement of women in the gardens was also increased. Training in women's home gardens was therefore considered to be an effective intervention (pp 97-107).

4. Food insecurity worldwide derived from food supply patterns: Eduardo Botti and Homero Dewes related malnutrition to food supply patterns (FSPs). They found that the worst conditions were in Southern Africa with a high prevalence of childhood overweight and Southern Asia with a high prevalence of childhood underweight, while populations with the best nutritional status were in Eastern Asia (pp 109-120).

\section{Governance}

1. India's export ban on rice during the global food crisis of 2007-08: Ben Groom and Mehroosh Tak found that the net impact of the export ban was positive in that it cushioned $84 \%$ of the Indian population against the adverse effects of the crisis (pp 121-141).

2. Integration of the Vietnamese rice market with the world market during the $\mathbf{2 0 0 8}$ food crisis: The Vietnamese government limited rice exports during the crisis in order to shield the local people from the international price rise. However, according to Jonas Luckman and associates it was thought to be more efficient to implement food security programs and public safety nets for the poor rather than insulate the whole country from the world market (pp 143-157).

3. Increased maize productivity in Ethiopia: Tsedeke Abate and associates point out the key role of government in the doubling of maize yields in Ethiopia. Government support of sustained investment in agricultural research took the form of improved maize varieties, better ratio of extension workers to farmers than other East African countries and increased use of mineral fertilizers (pp 965-981).

\section{Markets}

1. Welfare impacts of smallholder farmers' participation in maize and pigeonpea markets in Tanzania: Frank Mmbando and associates conclude from their study that better market information, rural infrastructure and household capacity to produce surplus production are critical to the improvement of household welfare (pp 1211-1224).

2. Household wealth and adoption of improved maize varieties in Nepal: A double-hurdle approach: Using Cragg's double-hurdle model for adoption of improved maize varieties, Wen-Chi Huang and Raju Ghimire conclude that the government should establish a wide seed distribution network in rural areas, preferably by way of public-private partnership (PPP), if widespread adoption is to be achieved. Also by linking farmers with potential buyers, transaction costs would be reduced, resulting in more profitable agriculture (pp 1321-1335).

\section{Nutrition, food security and safety}

1. Maize sufficiency, crop diversity and quality of diet in Malawi: Sieglinde Snapp and Monica Fisher found that crop intensification through subsidies improved dietary quality through direct cropping and by commercialization of improved maize varieties, providing income for purchase of diverse foods (pp 83-96).

2. International agricultural research to reduce food risks: Taking the example of aflatoxins, which cause around 90,000 cases of liver cancer each year, Delia Grace and associates describe combining several resistance traits in the breeding of resistance of maize to the Aspergillus species producing the toxins and also a method for their biocontrol (pp 560-582).

3. Household food insecurity in Eastern Cape Province, South Africa: Lovemore Musenwa and associates found that two-thirds of households were severely food insecure, the main cause being abandonment of own food production. They suggest that food security would be improved by increasing per capita incomes and the capacity to farm (pp 647-755).

4. Nutritional benefits from dairy production in Tanzania: Michael Kidoido and Luke Korir found that consumption of dairy products in low-income households was associated with reduction in stunting, underweight and wasting. Facilitating the production of dairy products therefore would be of considerable nutritional benefit to such households and would also improve their income (pp 681-692).

5. Nutritional adequacy of food supplies: Joanne Arsenault and associates estimated the micronutrient contents of national food supplies of Bangladesh, Senegal and 
Cameroon. Out of eight micronutrients the supplies of six were inadequate in Bangladesh and Senegal and three were inadequate in Cameroon. The authors suggest that the situation could be largely remedied by using the crops currently available and by crop diversification (pp 493-707).

6. A conceptual framework for understanding the impacts of agriculture and food system policies on nutrition and health: Rebecca Kanter and associates present verbally and diagrammatically a framework which depicts key relationships among agriculture, food systems, nutrition and public health. The framework is aimed at policymakers as the users and is relevant to a range of country contexts (pp 761-777).

7. Food consumption patterns and dietary diversity in eastern India: Sninoj Parappurathu and associates, as a result of their village level studies, emphasize the importance of obtaining a proper understanding of the socio-economic setting of a region in order to focus dietary and nutrition security interventions effectively (pp 1031-1042).

8. Does Ethiopia's Productive Safety Net Program improve child nutrition? Bethelhem Debela and associates found that Ethiopia's Productive Safety Net Program is providing positive short-term nutritional benefits for children, especially in those households that are able to leverage underemployed female labor (pp 1273-1289).

\section{Economic events and policies in relation to food insecurity}

1. Feeding more than 9 billion by 2050: challenges and opportunities: In an introduction to papers arising from an OECD conference with this title, Quentin Grafton and associates point out that business as usual will not deliver on either food availability or sustainable ecosystems. Rather, focus should be on factors that promote greater production but not at the expense of critical environmental functions (pp 179-183).

2. Food and water gaps to 2050: In this paper Quentin Grafton and associates introduce the global food and water system (GFWS) platform. Preliminary results indicate that crop-based food supply will be able to meet demand by 2050 but only with input intensification but some countries, especially in South Asia, will face deficits (pp 209-220).

3. Food security policy assessment in the Punjab, Pakistan: Muhammad Bashir and Steven Schilizzi suggest that further research is required to assess the potential of food security policies as much of their effectiveness is lost owing to poor implementation pp. 1071-1089).

4. Subsidies promote smallholder use of drought tolerant maize in Malawi: Stein Holden and Monica Fisher found that the main driver of a substantial increase in the cultivation of drought tolerant maize from 2006 to 2012 was the Malawi Farm Input Subsidy Programme, which provided seed of the varieties (pp 1225-1238).

5. Impact of agricultural technology adoption on asset ownership: the case of improved cassava varieties in Nigeria: Bola Awotide and associates showed that the adoption of improved cassava varieties may play a key role in strengthening asset ownership among smallholder farmers in Nigeria (pp1239-1258). 